\title{
Persons with disabilities and coronavirus disease (COVID-19) in Latin America and the Caribbean: status and guidelines
}

\section{Summary}

In the context of the global coronavirus disease (COVID-19) pandemic, the Economic Commission for Latin America and the Caribbean (ECLAC) is preparing a series of short publications with relevant policy recommendations for this period. This note offers a number of recommendations to address the impact of COVID-19 on persons with disabilities in the region.

\section{Introduction}

More than 70 million persons with disabilities live in Latin America and the Caribbean (ECLAC, 2014). They are a diverse group and experience multiple and simultaneous forms of discrimination on the basis of socioeconomic status, gender, age, place of residence, ethnoracial status and migration status, among others. Persons with disabilities were already among the most excluded in our societies before the COVID-19 pandemic and they, along with their families, will be among the most affected by this health crisis and its devastating social and economic impacts. This will only deepen the exclusion and marginalization that they experience.

The link between poverty and disability is one of the factors underlying the persistent exclusion of persons with disabilities. Studies on the relationship between disability and poverty agree that it is complex and interdependent, operating through various channels. Disability is both a cause and a consequence of poverty. Generally speaking, people living in poverty may be in poor health and have limited access to services to treat these problems; they also often lack adequate nutrition, live in substandard housing without access to safe drinking water and adequate sanitation, perform hazardous work and live in areas where they are exposed to different forms of violence - all of which may increase their chances of developing a limitation (ECLAC, 2019a).

In addition, there are several factors that can make persons with disabilities more vulnerable to living in poverty. From a life-cycle perspective, excluding a child with a disability from the education system results in low educational attainment, which impairs the child's subsequent chances of obtaining decent work, with sufficient income and access to social protection (ECLAC, 2019a). This exclusion is caused by barriers of various types: accessibility (for example, the physical accessibility of schools and transport); the school context (for example, teacher training, learning materials, adapted curricula); financial and, fundamentally, the attitudes of teachers, and of students and their parents (ECLAC, 2019b).

The integration of persons with disabilities into work is adversely affected by the lack of accessibility in public roads and workplaces, the lack of reasonable accommodations necessary to ensure the full exercise of the right to work under equal conditions, and discrimination and the persistence of negative stereotypes. In the workplace, some of the obstacles faced by persons with disabilities operate at the individual level (low technical

\section{Summary}

Introduction

A. Impacts of COVID-19 on the population with disabilities in Latin America and the Caribbean

B. Recommendations Bibliography

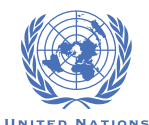

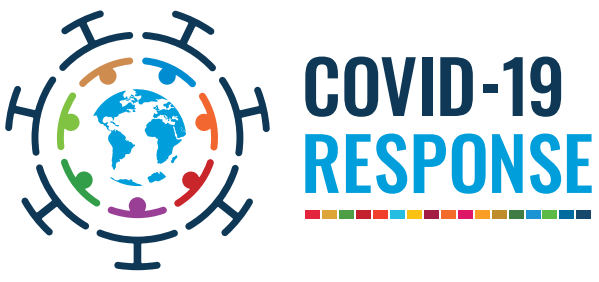


qualifications and low levels of soft skills) and family level (low family expectations and family overprotection); or else they arise from barriers in the environment (interruptions in the chain of accessibility from home to the workplace) and those faced in workplaces (ignorance, lack of experience with disability and a non-inclusive culture). As a result, persons with disabilities experience higher unemployment rates and are more likely to be economically inactive than those without disabilities. If they are working, they are more likely to have low-paying, informal and unstable jobs with limited career prospects (ECLAC, 2019b).

Moreover, even when controlling for income, households whose members include a person with a disability will incur higher expenses owing to the costs associated with specialized health, rehabilitation and education services, the purchase and maintenance of assistive devices, medicines and transport, among other things. In addition, meeting the care needs of a person with a disability may force another household member, often a woman, to withdraw from the labour market, thereby reducing household income. When there are no support mechanisms to cover or subsidize these costs and needs, they must be paid for by the family, which can further compound the situation of those living in poverty or cause families to fall into poverty (ECLAC, 2019a).

\section{A. Impacts of COVID-19 on the population with disabilities in Latin America and the Caribbean}

At the time of writing, there were 62,526 confirmed cases of COVID-19 and 2,641 deaths from the virus in the region. ${ }^{1}$ Although there is little epidemiological information on the risk factors associated with COVID-19, it has been established that both cases and mortality occur primarily among older persons. At present, there are no data on the disability status of those who have fallen ill or died. However, there is a positive relationship between age and disability, so it is reasonable to assume that some of the older persons who have contracted or died from COVID-19 also had a disability of some kind. In addition to their age profile, persons with disabilities are at greater risk from COVID-19 because of their limited ability to protect themselves from infection or to seek diagnosis and treatment, owing to the lack of information about the virus in accessible formats and poor accessibility to health facilities. At the regional level there is very little information on the population with disabilities in institutions, because the main instruments for collecting information on this population - population and housing censuses - do not collect information on these establishments (ECLAC, 2014). However, persons with disabilities living in institutions and community-based residences are particularly vulnerable to COVID-19, given the limited options for social distancing and the physical conditions of these facilities.

One of the areas where the impacts of the pandemic are already being felt is employment. According to ECLAC, the sector most affected by social distancing and quarantine measures is the services sector, which is dependent on interpersonal contact. In the region, the sectors that could suffer the greatest contractions - commerce, transport, business services and social services - provide $64 \%$ of formal employment. In addition, $53 \%$ of employment in the region is in informal activities, which will be greatly affected because they are heavily based on interpersonal contact (ECLAC, 2020). Considering that persons with disabilities already had a weak position in the labour market and significant participation in the services sector and informal employment, this population is likely to be particularly affected by the adverse labour market scenario during the crisis and the recovery period. Although specific data in this regard are scarce, research in Paraguay estimated that $40 \%$ of persons with disabilities in the country became unemployed after the start of the quarantine, with significant impacts on their household incomes (ABC Color, 2020).

The school environment also presents particular complexities for students with disabilities and their families in the context of the pandemic. According to ECLAC, as at 20 March 2020, 16 countries (Argentina, the Bolivarian Republic of Venezuela, Chile, Colombia, Ecuador, El Salvador, Guatemala, Honduras, Jamaica, Panama, Paraguay, Peru, the Plurinational State of Bolivia, Saint Lucia, Trinidad and Tobago, and Uruguay) had suspended classes at all

1 Data from the World Health Organization (WHO, 2020) as of 13 April 2020. The figures do not include information from Canada and the United States. 
levels of education, and Brazil had imposed localized closures. The disruption of activities in educational establishments will have significant effects on the learning of students with disabilities and could also affect their nutritional status, as many students from vulnerable households, including children and adolescents with disabilities, depend on school meals programmes. Although plans have been made to promote the use of digital devices in education systems, there are gaps in access to computers and the Internet and limitations in skills for their home-use by persons with disabilities (Ullmann and others, 2018). The closure of educational establishments and the transfer from teachers to parents (mainly mothers) of much of the responsibility for accompanying and supporting learning also presents a challenge if parents lack the skills and teaching techniques to meet the learning needs of children with disabilities.

The physical confinement that has been enforced in many countries in the region to curb the transmission of the virus may impede access to goods and services that are essential for the well-being of persons with disabilities. This is especially critical in the case of health, rehabilitation and care services, but also in the case of medicines, diapers, assistive devices and special foods, among other goods. Confinement and travel restrictions can also aggravate conditions for persons with certain types of disabilities, for example, those with autism spectrum disorder (ASD), for whom routine helps to reduce stress and anxiety. The well-being of those with ASD and their families can be adversely affected by the disruption of routines owing to confinement. Confinement can increase exposure to domestic violence for women with disabilities, who are more likely to be victims of such violence than women without disabilities.

\section{B. Recommendations}

Respect the fundamental and inalienable rights of all persons in the context of the crisis and in the recovery period, regardless of their disability status, and address in particular subgroups of the population that may be particularly disadvantaged, such as women, children and adolescents with disabilities. This pandemic puts pressure on the scarce resources of health systems, so it is essential to ensure that goods and services are provided without discrimination and that everyone has equal access to government-run mitigation programs and services.

Ensure that all information related to the crisis is accessible. This includes public health information to prevent, detect and treat COVID-19 and information on the measures implemented by governments to address and mitigate the socioeconomic impacts of the pandemic, to ensure that persons with disabilities can be informed about entitlements they can access in the context of the crisis and in the recovery period. This information must be made available in sign language and in simple, easy-to-read language, and in accessible media, modes and formats, including digital technology, subtitles, relay services and text messages.

Ensure accessibility at testing sites for COVID-19 diagnosis and treatment. This includes the physical accessibility of these facilities, the possibility of adapting hospital machinery and other medical supplies to persons with disabilities requiring treatment, as well as access to sign language interpreters, among others.

Strengthen non-contributory social protection entitlements for persons with disabilities and their families. Many countries in the region already have targeted pensions or cash transfers for persons with disabilities, for whom different selection criteria are applied (for example, regarding the recipient's inability to work or the household's income level). However, the amount of these pensions or transfers tends to be low, difficulties arise in the selection of recipients and records, and the processes for certifying disability are cumbersome (Ullmann and Atuesta, 2020). The low amounts of these pensions and transfers are not commensurate with the high levels of poverty in households with persons with disabilities and the additional costs of having a family member with a disability, which would justify differentiated and higher transfer amounts than those for the population without a disability (Ullmann and Atuesta, 2020). 
Ensure that measures taken to address the crisis and during the recovery period incorporate the disability perspective, including measures relating to health, employment protection and educational continuity. The pandemic offers the countries of the region an opportunity to mainstream a disability approach into public policy and thus protect the rights and well-being of this population group.

Create or expand spaces for participation and consultation with organizations of persons with disabilities. Throughout the process of designing and implementing policies to address and mitigate the impacts of COVID-19, these organizations will be able to respond to and properly address the needs of persons with disabilities, respecting their rights and dignity. Such consultations may also shed light on the possibilities for persons with disabilities and their organizations to contribute to tackling COVID-19.

Ensure the continuity of work and education and the provision of rehabilitation services for persons with disabilities through information and communication technologies (ICT). While ICTs can be a key tool to limit the negative impact of confinement and physical distancing on the lives of persons with disabilities and their families, access to technologies needs to be strengthened from a financial point of view. In this regard, governments should explore options for promptly subsidizing the acquisition of technologies for persons with disabilities, as well as training in their use. Alternatively, they may explore the use of other devices, such as radio and television, to which households with persons with disabilities do have access

Provide psychosocial support to persons with disabilities and their families and strengthen support networks for persons with disabilities.

Adopt flexibility in restrictions on movement in public spaces for persons with disabilities and consider the possibility of establishing differentiated opening hours in shops for persons with disabilities and other groups vulnerable to the virus.

Improve the statistical information collected during and after the crisis, so that countries will have disaggregated information on the differentiated impacts of the COVID-19 pandemic on certain population groups, including persons with disabilities. 


\section{Bibliography}

ABC Color (2020), "El 40\% de personas con discapacidad quedaron desempleadas durante cuarentena", 6 April [online] https://www.abc.com.py/nacionales/2020/04/06/el40-de-personas-con-discapacidad-quedaron-desempleadas-durante-cuarentena/.

ECLAC (Economic Commission for Latin America and the Caribbean (2020), "Latin America and the Caribbean and the COVID-19 pandemic: economic and social effects", Special Report, No. 1, Santiago.

(2019a), Critical obstacles to inclusive social development in Latin America and the Caribbean: background for a regional agenda (LC/CDS.3/3), Santiago. (2019b), Social Panorama of Latin America, 2018 (LC/PUB.2019/3-P), Santiago (2014), Regional report on measuring disability: overview of the disability measurement procedures in Latin America and the Caribbean (LC/L.3860(CE.13/3)), Santiago.

Ullmann, H. and B. Atuesta (2020), "Las transferencias monetarias no contributivas: un instrumento para promover los derechos y el bienestar de la población infantil con discapacidad en América Latina y el Caribe", Project Documents, Economic Commission for Latin America and the Caribbean (ECLAC)/United Nations Children's Fund (UNICEF), forthcoming.

Ullmann, $\mathrm{H}$. and others (2018), "Information and communications technologies for the inclusion and empowerment of persons with disabilities in Latin America and the Caribbean", Project Documents (LC/TS.2018/48/-*), Santiago, Economic Commission for Latin America and the Caribbean (ECLAC).

WHO (World Health Organization) (2020), "Coronavirus disease 2019 (COVID-19) situation report - 84" [online] https://www.who.int/docs/default-source/coronaviruse/ situation-reports/20200413-sitrep-84-covid-19.pdf?sfvrsn=44f511ab_2.

This document is part of a series of reports prepared by the Economic Commission for Latin America and the Caribbean (ECLAC) on the evolution and effects of the COVID-19 pandemic in Latin America and the Caribbean. It was prepared by the Social Development Division, directed by Simone Cecchini, under the general coordination of Alicia Bárcena, Executive Secretary of ECLAC.

Copyright (c) United Nations, 2020 